\title{
UNANTICIPATED PROBLEMS IN THE UNITED STATES CHILD PROTECTION SYSTEM
}

\author{
Kathleen Coulborn Faller, MSW, PhD \\ University of Michigan Interdisciplinary Project on Child Abuse and Neglect and School of Social Work, $1015 \mathrm{E}$. \\ Huron, Ann Arbor, MI 48109
}

\begin{abstract}
While the United States child protection system is widely recognized as probably the most sophisticated and wide-ranging in the world, it nevertheless has some inherent problems. This article addresses some of the negative effects of mandatory reporting and the lack of fit of a short-term crisis intervention treatment approach for a substantial proportion of the protective services population. Reporting may have detrimental effects on the clientreporter relationship. Further, over half of the cases investigated are not substantiated. Of concern are the impact on innocent families of being investigated and the waste of scarce worker resources on investigation. While some protective services families are well suited to a crisis intervention model, a large number are multiproblem families who are always in crisis and families with chronic problems for whom crisis intervention is totally inadequate. Furthermore, because of high caseload size, workers are often not available to intervene after they have investigated the case. The problems described have been exacerbated by funding cutbacks under the current United States administration. The child protection system, along with other social welfare programs, is at risk for being dismantled by the Reagan administration.
\end{abstract}

Résumé-Bien que le système de protection de l'enfance américain soit très élaboré et étendu par rapport aux systèmes en fonction ailleurs dans le Monde, il n'en reste pas moins qu'il rencontre quelques difficultés inhèrant à sa structure. Le présent article fait état d'essais contre-productifs liés à la dénonciation obligatoire et au défaut que représente l'absence de possibilités d'intervenir rapidement et à court terme de la part des services protecteurs de l'enfance. Parmi les dangers de la dénonciation obligatoire, on trouve par exemple les fausses dénonciations, le nombre excessif de dénonciations non réellement justifiées, et ces excès sont dangereux car ils augmentent les tensions pouvant conduire à la violence dans des familles qui n'ont pas encore en fait passé à l'acte. En fait plus de la moitié des cas soumis à enquête se révèlent ne pas être des cas réels. Non seulement l'excès d'enquêtes fait du tort aux familles mais aussi il représente un gaspillage des forces des travailleurs sociaux en nombre déjà insuffisant. L'intervention de crise n'est pas approprié à la situation de familles qui ont déjà des problèmes chroniques et multiples. Les difficultés sont actuellement exacerbées par le manque de fonds et les diminutions de ceux-ci imposées par l'administration gouvernementale des Etats-Unis à l'heure actuelle. On peut aller jusqu'à dire que le système de protection de l'enfance, de même que d'autres programmes de bien-être social, courent actuellement le risque d'être démantelés par l'administration du Président Reagan.

IN THE LAST TWO DECADES we have seen a prodigious growth in the child protection system in the United States. Most professionals involved in child abuse and neglect regard it as one of, or perhaps the most, sophisticated and highly developed system for handling this very troubling problem. Like many other social engineering endeavors, the system has a number of unanticipated and unintended negative consequences for families and children who are channeled into it. Some of these are inherent in the system itself, and others are a consequence of inadequate funding. Professionals who are involved in the further evolution of the child protective system must examine problems from both sources, acknowledge their impact, and work to alleviate those which can be successfully dealt with. The purpose of this paper is to describe some of these problems, to illustrate them with case examples, and to suggest areas for additional study. The paper does not intend to suggest that current structure should be scrapped, but rather to point out some of the shortcomings. The issues to be

Presented at the Fourth International Congress on Child Abuse and Neglect, Paris, 1982. 
addressed include some negative consequences of the reporting requirements, assumptions made about the most appropriate form of intervention, and the impact of funding cut backs in the child protection system.

\section{REPORTING REQUIREMENTS}

Most central to the transformation of the child protection system has been expansion of the reporting requirement. Each state has its own child protection statute and resulting system for handling abused and neglected children. Before 1960, the structure for case identification in most states was permissive, that is, persons could report suspected cases but did not have to. Further reporting statutes were, as a rule, restricted to physicians and to cases of suspected child abuse [1]. Neglect was not generally included.

In the 1960s and 1970 s all 50 states passed new child maltreatment reporting laws whose uniformity has been enhanced by federal guidelines tied to funding. While some variability among states persists, most states not only include reporting of child abuse, but also neglect and child sexual abuse [2]. Further, referral of suspected cases is now mandatory for certain people; that is, they must report under threat of negative sanction for failing to do so. There has also been a dramatic expansion of persons who must and may report. Thus reporters are no longer only physicians, but also nurses, teachers, day-care providers, law enforcement personnel, social workers, and other mental health professionals. Such persons must report when "they have reasonable cause to suspect child abuse or neglect" [3]. Some states include potential, as well as actual harm to the child, as reportable. In a number of states, everyone. not just certain professionals, must report. In other states, persons not specified by profession are permissive reporters and they may report [4].

A point that deserves emphasis because it has important implications is the standard of certainty the person needs to have when the report must be made. "reasonable cause to suspect." Thus, we have now developed a child protection system which casts a very wide net. A whole range of professionals who have contact with children must make a report and others may do so. All manner of suspicious circumstances, possible physical abuse, physical neglect, sexual abuse, and emotional maltreatment are included.

Furthermore, the definitions of abuse and neglect which reporters must rely upon are quite general. For example, the language in the Federal Statute, the Child Abuse Prevention and Treatment Act, passed in 1974, defines child abuse and neglect as "the physical or mental injury, sexual abuse, negligent treatment, or maltreatment of a child under the age of 18 by a person who is responsible for the child's welfare under circumstances which indicate that the child's health or welfare is harmed or threatened thereby" [5]. Professionals are left to their own devices as a rule in deciding whether a specific concern fits under one of these general categories.

\section{Reporting Issues for Professionals}

An abiding concern for those who must refer their clients to protective services is the impact upon the relationship they have with the client, as well as the impact of the system on the client. The reporting professional may be the family's only lifeline to a helping person. and the referral may sever this lifeline. Issues of trust building with clients may become very complicated. Clients may not open up in therapy for fear of being reported. Research findings from the National Incidence Study document that mandated professionals only report onefifth of the cases of which they are aware [6]. Whether they fail to make reports because of their concern about the referral's impact upon their relationship with the client or the impact of the child protection system on clients or for other reasons is yet to be studied. 
Further, professionals may subtly, or not so subtly, tell their clients not to reveal child maltreatment because the professional wants to avoid having to report. For example, recently the author was consulted by a social worker who told a father and mother, both of whom were sexually abusing their 14-year-old daughter, not to give her information about the abuse or she would have to report them.

\section{Impact of Reporting on Family}

Another impact issue is what happens to the family once it has been reported. Although statistics vary from community to community, as well as over time, under half of reported cases are substantiated in the investigation process [7]. While inability to substantiate may occur because a family has been able to successfully cover up the incident or the worker lacks investigative skill, probably the majority of cases which are denied are ones where a parent or parents have been falsely accused. Allegations by nonprofessional reporters are more likely to be incorrect than those made by mandated reporters. For example, in the National Statistics from $1980,35 \%$ of reports from nonprofessionals were found to be true as compared to $47 \%$ of referrals by professionals. When anonymous reports are combined with nonprofessional ones, the substantiation rate is $31.4 \%$ [7]. Similarly, in the 1981 Michigan data, $53 \%$ of reports from mandated reporters were verified, while only 35\% from permissive reporters were [8].

Recognizing that the necessity of identifying children at risk is important enough to override potential harm to families falsely accused, we must nevertheless be aware of the impact of investigation. How do parents experience the protective services involvement? Generally, the investigation begins with a face-to-face confrontation of the parent by the worker, in which the worker discusses a list of allegations with the parent. While the worker may attempt to be supportive and may present her/himself as someone who can help, the essential message to the parents is that they have failed as parents. Whether the accused are good parents who have been mistakenly identified, marginal parents who receive many messages that they are inadequate in the role, or maltreating parents whose children are at risk, the impact of being investigated can be devastating. For many adults, good and bad parents alike, the role of mother or father is at the core of their identity. Responses are variable: selfdoubt, fear of losing their children, anger at the investigator, preoccupation with the identity of the reporting person, or anger at the reporter if she/he is known.

A couple whom the author interviewed was able to reflect on their experience of being subjected to a protective services investigation because their l-year-old son had failure to thrive. They described how devastating it was not only to feel that they were responsible for their son's problems, but also to have their parenting techniques scrutinized, their marital problems uncovered, and their families of origin taking sides and blaming one or the other of them. Ultimately their son was found to have a rare organic illness causing his growth retardation.

A further irony is that the protective services investigation itself can increase the level of stress in the home and place the child at greater risk than before. Thus the system we have instituted to enhance our ability to identify children and intervene to help them may have very negative consequences for parents and their children. These consequences impact not only on the guilty but on the innocent as well.

\section{Increase in Reported Cases}

Another result of the expanded reporting requirement is an astronomical increase in the number of cases reported. Beginning in 1976, the first national statistics became available with just over 400,000 cases being reported. In $1980,788,844$ cases were reported, an increase of $91 \%$ [7]. Because of increased caseload size and the emergent nature of a substantial 
proportion of referrals, emphasis in most child protective work is on investigation and protection, and treatment to change the circumstances leading to the maltreatment takes second place. That is, families are identified as being abusive or neglectful, and then little is offered to them in terms of help to improve their abilities.

For example, a mother and stepfather had their two children, ages 9 months and 24 months, placed temporarily in foster care. The 9-month-old was suffering from medical neglect because the parents were not following through on treatment of her asthma, and the 2year-old had multiple bruises and scars, some of which were nonaccidental. After four months of waiting for treatment, the family was told to find a psychiatrist who would accept Medicaid and who would be willing to treat them. Medicaid would cover ten visits.

\section{CRISIS INTERVENTION}

There is a second important characteristic of the child protective system in the United States which needs to be critically examined. The system is based upon an underlying clinical assumption that what abusive and neglectful families need in order to more adequately care for their children is some type of crisis intervention. That is, parents have maltreated their children because the family is under stress. The strategy of the child protective worker is to reach out to families while they are in crisis and work intensively with them so that they will develop more adaptive ways of coping with stress.

Therefore, in most states, the child protective system is structured in such a way as to focus on short-term intervention. The state systems anticipate family situations being resolved within the time span of three months to two years. Cases requiring long-term intervention are regarded as the exception rather than the rule. This assumption about the client population suggests wishful thinking on the part of legislators and professionals, and/or a failure to carefully assess the target population. While stress and crisis play an important role in many cases of child maltreatment, they do not in all. Stress, particularly situational stress, is more likely to be a factor in physical abuse than neglect [9]. However, neglect is at least twice as prevalent among reported cases as abuse [7, 8].

Moreover, many maltreating families experience chronic multiple crises. For them there is no opportunity to reach a new and more adaptive state of functioning as a result of crisis intervention. Before this can happen, the family system is reeling under the impact of a new crisis. For example, a single family may have one or more family members with ongoing medical emergencies, an adult with a severe drinking problem, financial problems which threaten them with eviction or loss of utilities, trouble with neighbors, trouble with the police. trouble with the schools, and unwanted pregnancies.

Furthermore, many protective services problems do not represent a stress-related breakdown in family functioning. Some maltreating parents are mentally retarded, or they have children who have long-standing serious physical or mental problems. Cases of this sort require ongoing support and services, often until the children reach majority. If children are to remain in homes with these kinds of problems, the community must accept the responsibility of compensating for familial deficiencies on a long term basis. A crisis intervention type of service is totally inadequate.

Another irony of the present condition of the child protection system is that because of high caseloads, workers are not available to reach out and work intensively with families. Often all the worker is able to do once a case has been investigated is to monitor. Families may be referred to other agencies for treatment, but such agencies tend to be much more traditional in their approach. Rarely do their workers go to families' homes and work intensively. Frequently, such agencies do not focus on concrete problems and stresses, such as inadequate housing or unemployment, as factors appropriate for their intervention. Their 
expectation is that families will come to the office on a regular basis, usually weekly and talk about their problems. Such an approach is poorly suited to the majority of the protective services population. Clients tend to be overwhelmed by their concrete circumstances, and often lack the motivation, verbal skills and insight capability necessary for talking therapy.

Thus, protective services families are unlikely to form therapeutic alliances with professionals in traditional agencies, if such services are available to them, and may only be monitored by the protective services worker. At the end of six months or a year, if there has been no egregious incident of maltreatment in the meantime, the case will be closed. No real change will have taken place in family functioning. The major effect of protective services intervention will have been to label the family. Such families are very vulnerable to subsequently maltreating their children. They are likely to be reported again and investigated by the child protection system. About one-third of families coming into the system at this time have previously been referred, some of them several times $[7,8]$.

\section{IMPLICATIONS OF PRESENT FISCAL SITUATION}

Some of the dilemmas just described, which are aspects of the current child protection system, have been exacerbated by the funding situation. Two things the current system desperately needs are increased numbers of workers with good training and supervision, and funding for the development and implementation of innovative treatment programs for the protective services population. When reporting requirements first generated increased numbers of cases, the casework staff began expanding to address growing needs. Similarly there were efforts at the federal level to fund demonstration intervention projects in order to discover how to successfully intervene with abusive and neglectful families. Further, at the state level, there was encouragement and funding for innovative treatment projects. Unfortunately, movement in the direction of adequate caseload size and fledging efforts at treatment development have been substantially inhibited by the funding cutbacks of the Reagan administration.

The implications of our present fiscal and service situation are most upsetting. We have laws in place which continue to result in increased reporting of suspected child abuse and neglect at a point in our political history when there are severe cutbacks in monies for social welfare services, including services to children who have been abused and/or neglected. This has exacerbated the tendency of the system to label families without providing adequate intervention.

\section{STRATEGIES TO ADDRESS CHILD PROTECTION SERVICES PROBLEMS}

What can be done to address some of the problems inherent in the system within the current fiscal context? There are no easy answers. However there are training, research, and advocacy strategies which can help to address the problems outlined in this paper.

\section{Training}

First, serious consideration should be given to training mandated reporters to more accurately identify child abuse and neglect. Half of the time they are wrong. Emphasis should be placed upon how parental behavior is harming the child. Training should focus less on the broad categories of abuse and neglect and more on specific types of abuse and neglect, such as burns, a range of types of sexual abuse, educational neglect, medical neglect, and growth failure and when these troubling conditions constitute child maltreatment. Another useful 
component of such a training effort might include how to use other referral resources when they are more appropriate. Resources might include public health nurses, homemakers, prevention programs for high risk families and day-care.

Such an approach would necessitate clarification of definitions of child maltreatment by the child protection system and training of workers in this area. One of the current problems is that there is considerable variability from community to community as well as from worker to worker, as to which cases are accepted and which ones are denied.

If erroneous referrals could be reduced, fewer cases would need to be investigated. Workers would then have more time for the cases which would enter the system, and time for both investigation and treatment.

\section{Further Research Required}

Second, systematic research is needed to look at why mandated reporters do not report, the effects of reporting on client-reporter relationships, and the impact on families of being investigated by the child protection system. At the present time, we know that there is vast underreporting [6], but no systematic efforts have been made to find out why this is so. Further we have only anecdotal information about the effects of reporting on therapeutic relationships and the impact of investigation on clients. Research in these areas could well lead to planned changes in the child protection system. Once the problems are more fully understood, they can be addressed by program change.

\section{Documentation of Effects of Intervention}

Third, what is desperately lacking is careful documentation of the effects of the intervention on families. Michigan is the only state which has looked at the impact of the system, but focused mainly on recidivism rates among protective services cases, but this study has not been widely disseminated [10]. We must build on some beginning research which suggests types of intervention that are successful with abusive and neglectful families [10, 11]. We need to find out more about what kinds of services are effective with what types of clients. Of importance is the identification of those families who will not respond to any of our present intervention techniques. These need to be differentiated from those who require intensive, outreach, nontraditional services, but who will respond. It is also important to devise maintenance strategies for chronically troubled families. Finally, we must identify cases where there is a situational crisis and which cases can respond to the current service delivery system. The results of such research efforts would probably lead to a more highly differentiated system with different approaches for different types of families.

\section{CONCLUSIONS}

However, new research and training efforts cannot be mounted without funding. Not only does the current fiscal situation preclude innovation but the current structure of service delivery has been eroded by budget cuts. We must not allow the present fiscal conservatism in the United States to dismantle the child protection system, and to destroy the gains in services we have made for children. We must insist that caseloads be made manageable, and that service monies be reinstated. We must resist exhortations to turn to our communities and to volunteers for services which we as a society owe to children. It is not a privilege to grow up in an environment free from from harm; it is a right. Professionals concerned about children need to persist in putting that message to legislators and to the public. We must 
enable the developing system which protects children to rid itself of its negative features and develop further so that it fulfills its mandate.

In conclusion, while dramatic gains have been made in the United States in our efforts to protect children, the time has come to carefully examine the child protection system and to address its flaws. In the midst of this effort, we must fight to secure increased funding and to restore lost resources. These cutbacks have exacerbated existing problems in the system and have created new ones.

\section{REFERENCES}

1. Child Abuse and Neglect: The Problem and Its Management, Vol. 1, An Overview of the Problem, DHEW Pub \#(OHD) 74 30073, p. 34. Government Printing Office, Washington, DC.

2. Child Abuse and Neglect: The Problem and Its Management, Vol. 1, p. 34-36. (1977).

3. Michigan Statute, Child Protection Act, (1975).

4. Child Abuse and Neglect: The Problem and Its Management, Vol. 1, p. 38-39.

5. Child Abuse and Neglect: The Problem and Its Management, Vol. 1, p. 3.

6. Executive Summary: National Study of the Incidence and Severity of Child Abuse and Neglect. OHHS Publication \# (OHOS) 81-30329, Government Printing Office, Washington, DC (1981).

7. Highlights of the 1980 National Reporting Data. American Humane Association, Englewood, CO (1982).

8. Michigan Protective Services Management Information System (PSMIS), Lansing, MI (1981).

9. FALLER, K. C. Social Structural Variables in Families that Abuse and Neglect Their Children, doctoral dissertation. University of Michigan, University Microfilms, Ann Arbor, MI (1981).

10. COLLIGNON, F. and ZAKIAN, A. Testing Measures of Perfor mance for Protective Services. Berkeley Planning Associates, Berkeley, CA (1980).

11. Evaluation of Child Abuse and Neglect Demonstration Projects, 1975-1979, Vol II. Summary. U.S. Department of Commerce, Washington, DC (1977). 